\title{
Strategic groups based on marginal rates: An application to the Spanish banking industry
}

\author{
Diego Prior $^{\mathrm{a}, *}$, Jordi Surroca ${ }^{\mathrm{b}}$ \\ a Department of Business Economics, Universitat Autónoma de Barcelona, Bellaterra (Barcelona) 08193, Spain \\ ${ }^{\mathrm{b}}$ Department of Business Administration, Universidad Carlos III de Madrid, Getafe (Madrid) 28903, Spain
}

\begin{abstract}
This paper uses Data Envelopment Analysis (DEA) to identify strategic groups (SGs) in the Spanish banking industry. The concept of SG relies on the fact that firms grouped together value inputs and outputs in the same way. As such, they take identical direction when, due to external influences, changes are required. Weights obtained from DEA are extremely useful in the valuation of inputs and outputs. Specifically, by comparing DEA weights pair-wise, i.e. quantifying the variables' marginal rates (MR), we can obtain a very good representation of the existent trade-off and the relative importance of the two variables.

The paper uses MRs obtained through DEA models and, simultaneously, proposes feasible ways to overcome two usual problems with DEA virtual weights, namely: (1) the multiplicity of weights for efficient DMUs; and (2) the inexistence of dual variables for inefficient DMUs.

From the empirical point of view, once the MRs are determined, the second stage is to perform Cluster Analysis. We apply Cluster Analysis in two ways: (1) on the basis of the MRs; and (2) following the traditional application by running Cluster Analysis with the original variables. The results obtained show the advantages of using MRs instead of the standard application of Cluster Analysis.

Summing up, the concept of SG is reinforced if we use refined methods to determine the existence of SGs. The results of the application of DEA models to observe the presence of SG in the Spanish banking industry offer interesting views on it.
\end{abstract}

Keywords: Data Envelopment Analysis (DEA); DEA weights; Banking; Strategic groups; Marginal rates

\footnotetext{
* Corresponding author. Tel.: +34 9358 11539; fax: +34 935812555.

E-mail addresses: diego.prior@uab.es (D. Prior), jsurroca@emp.uc3m.es (J. Surroca).
} 


\section{Introduction}

To manage organizations, knowledge of the im plicit trade offs among the activities is necessary. For example, to increase the production of a spe cific output, organisations must know how much additional quantity of a necessary input is re quired, or how much one input (output) should in crease when another input (output) decreases. This reasoning, taken from production theory, can also be applied when examining the choice of competi tive strategy made by a firm. For example, Porter (1980), when defining generic strategies of differen tiation and costs leadership, states that a firm's current trade offs indicate its capacity to adapt to new competitive market conditions.

In fact, according to Porter (1979, p. 215), the concept of trade off is already implicit in the very definition of a strategic group (henceforth an $\mathrm{SG})$. Thus, it is assumed that all firms that are in the same SG will respond to a disturbance is sim ilar ways, given that their costs of change in strat egy are very similar. Similarly, Hatten and Hatten (1987) make it very clear that the cost of a change in strategy within a SG is different from the rest of the SGs in the industry.

Pursuing this viewpoint, this study introduces an alternative approach of assigning firms to SGs: firms are classified according to their capacity to respond to disturbances, where capacity to re spond to disturbances is defined as the trade offs among key decision variables. In fact, the main motivation of this paper is to demonstrate that the traditional focus of the SG literature, which groups firms according to their similarities in key strategic dimensions, can be surpassed.

In our application, we have found the taxon omy proposed by Cool and Schendel (1987) to be very useful in the key variables selection proc ess. Cool and Schendel classify the strategic varia bles into scope and resource commitments variables. Later, this classification turns out to be of great help in the use of the non parametric, Data Envelopment Analysis (DEA) models to determine the response capacity of each strategic group.

The initial DEA model was proposed by Char nes et al. (1978). A DEA model performs compar isons among organisations (referred to as decision making units, DMUs), which use similar composi tions of inputs to obtain similar compositions of outputs. In our case, the DMUs are banking firms, the inputs are resource commitments and the outputs are dimensions of scope. The result is the construction of an empirical frontier, the configu ration of which is defined by different firms sharing the same commitment of resources in order to reach the maximum scope; i.e. to participate in a greater number of market segments, to offer a greater number of products in these markets, or to extend the geographic reach of its strategy. If a firm lies on the frontier (say, there is no other DMU producing more outputs by consuming equal or lower inputs), it is labelled a strategic lea der (SL). If not, it is a strategic follower (SF). DEA provides efficiency scores, and for SFs a set of peers that are obtained by projecting them on to the frontier. The efficiency score indicates the percentage by which a SF should increase its out puts in order to become efficient, i.e. become an SL. Reference units are hypothetical DMUs on the efficient frontier regarded as target units for SFs.

There exists a broad research stream using DEA models to evaluate efficiency in banking (see, for instance, Grifell Tatje and Lovell, 1997, or Pastor et al., 1997). However, as far as we know, previous literature using the DEA method ology to determine strategic groups is truly scarce. Day et al. (1994, 1995) reveal the indubitable advantages of this technique. In particular, they highlight the capacity to consider multiple outputs or the establishment of a nexus between inputs and output when firms pursue multiple objectives. Their proposal is valuable because it introduces a clear and objective criterion for identifying strate gic groups. It does, however, suffer from severe limitations: depending on the line segment to which they are projected, two practically identical firms can end up being classified in different SGs.

This paper applies DEA to identify strategic groups, but in another direction. To us, a SG is a set of firms that are similar because of the way they value inputs and outputs. This shifts the emphasis to the determination of weights. Thus, our proposal consists of grouping together firms 
according to similarities in their relative valuation of key decision variables (the trade offs between the relative weights). However, there are two tech nical problems that must be addressed first. First, for each efficient firm there is not just one but a multiple number of weights that could be used. Second, for DMUs that do not form part of the frontier, the weights are undefined. The latter problem arises from microeconomic theory.

This paper is organised as follows. Besides this introduction, there are five remaining sections. Section 2 gives an analysis of the theoretical foun dations of the SGs and closes with a proposal that helps to resolve the problems that arise when Clus ter Analysis is used directly to establish SGs. In Section 3, a variant of the non parametric DEA models is developed to determine the existing trade offs between each pair of strategic variables. Section 4 is methodological: it comprises a descrip tion of the sample, the strategic decision variables and the selection of marginal rates required to determine the presence of SGs in the banking industry. The results of the empirical application are reported in Section 5. The article ends with a synthesis of the principal conclusions.

\section{The strategic group concept: Multi- dimensionality and causality of the strategy}

The concept of SG was introduced by Hunt in 1972, although it was later contributions (namely Caves and Porter, 1977; Porter, 1979) defined the principal elements of the theory. According to Por ter (1979), the concept of the SG serves to distin guish a group of firms with similar strategies that, in turn, are different from those followed by other firms in the same industry. Thus, the strate gic decisions made by a firm within an SG cannot be imitated by firms outside the group without substantial costs (monetary, time or uncertainty about the outcome of such decisions). Accord ingly, the existence of SGs requires the existence of barriers to imitation (Caves and Porter, 1977; Porter, 1979). These group specific entry barriers, the so called "barriers to mobility", give protec tion to group members, and explain why some firms obtain positive economic benefits from adopting intra group strategies while others do not. Without such barriers, successful strategies could be imitated quickly, resulting in loss of per formance differentials (Porter, 1979). From this viewpoint, mobility barriers could be interpreted as the penalty costs of moving from one SG to an other: high mobility barriers mean the expected costs of any attempt to change group membership are high, which leads to lower expected profitabil ity. This eliminates the incentives to change among SGs and deters entry into groups (Hatten and Hat ten, 1987).

Obviously, there is a price to pay for changing strategies; and the more dissimilar a strategy is, the more it will cost to imitate it. Hence, firms in the same group will find it less costly to behave like the rest of the group members. In contrast, barriers to mobility between groups imply that non members suffer a high cost for copying the strategies of the group to which they do not be long. Consequently, each SG comprises firms fol lowing similar strategies about key variables. This also concurs with the definition by McGee and Thomas (1986) of an SG as a group of firms responding in the same way to environmental dis turbances. The result of this homogeneity is that a specific strategic dimension acquires increasing importance while other dimensions have decreas ing importance. In contrast, when we compare firms forming part of different SGs, the barriers (the costs of imitation) depend upon the relative circumstances of each firm, as costs functions may be asymmetric (Hatten and Hatten, 1987).

It follows from the previous discussion that a strategic group can be defined as a set of firms that organize themselves in the same way and react in a unified way to the same external influences. This is, precisely, the definition of SG we are interested in utilizing throughout the paper.

Basically, the SG framework relies on barriers to mobility to account for persistent intra industry performance variation (Porter, 1979). Although the existing literature has had relative success in the identification of groups of firms with different strategies (i.e., dissimilarities in the collective behavior between groups), no conclusive empirical evidence exists for the hypothesized group per formance linkage (McGee and Thomas, 1986; 
Thomas and Venkatraman, 1988; Barney and Hoskisson, 1990). There are two possible explana tions for the weak empirical evidence on the per formance implications associated with group membership. One possibility is that the relation ship has not been captured adequately (due to poor specification of the model). The other possi bility is simply that no such linkage exists (see, for instance, the work of Hatten and Hatten, 1987, who assume the concept of SG exists as an analytical convenience). Being more optimistic than Hatten and Hatten, and assuming that SG is something more than a methodological artifact, the literature identifies to two essential problems. First, there has been limited progress towards an acceptable definition of the concept of SG (Cool and Schendel, 1987). Recently, this lack of pro gress has led to the suggestion of new theoretical approaches to define SG such as, for example, the cognitive perspective (see Fombrun and Zajac, 1987) or the resource determinants of performance differences (see Dierickx and Cool, 1989; Mehra, 1996). The second problem identified is that the methodology for treating the data is inadequate (Ketchen and Shook, 1996); and the habitual use of Cluster Analysis is criticised (Thomas and Ven katraman, 1988; Barney and Hoskisson, 1990). Day et al. (1994, 1995) illustrate the crucial weak ness of this technique by showing that when firms are designing strategies; in fact, managers cognise a causal model (i.e. a transformation function) relating, in a more or less conscious manner, oper ational decisions with the attainment of an objec tive function. Furthermore, Day et al. (1994, 1995) report that firms are typically driven by mul tiple goals: not just profit maximization. There fore, Cluster Analysis is an inadequate technique because (i) it does not capture the multidimensio nality of strategy; (ii) it does not take into account the relative importance of the key decision varia bles (Hatten and Hatten, 1987); and (iii) because it does not allow the incorporation the inherent causality of the definition of strategy (Thomas and Venkatraman, 1988).

From the discussion of the literature below, it is our belief that (a) it is necessary to identify the causal model which helps to identify the character istics of the transformation function between the strategic variables; (b) it is important to know the relative weights of the key decision variables (i.e., the trade offs between the variables) in order to test the existence of mobility barriers among dif ferent SGs; and finally (c) it is beneficial to identify the strategic leaders (DMUs forming the frontier) and strategic followers (DMUs that are inefficient, despite forming part of the same $\mathrm{SG}$ ).

Given this conception of SG, the next section explains how to use DEA models in order to achieve the three objectives just mentioned.

\section{Using DEA to assess response ability}

Here, we attempt to eliminate the limitations raised in the previous section by using DEA mod els. Our final goal is the proposition of a three stage process, which tries to avoid the direct Cluster Analysis of the original variables. In the first stage, DEA is used to assess the degree of efficiency of each firm, allowing each firm to convert inputs into outputs autonomously. DEA efficiency scores are obtained by radially projecting all DMUs on to the frontier. A firm lying on the frontier is efficient. Such a firm is, as mentioned earlier, so called a "strategic leader", or SL. Otherwise, the DMU is inefficient and is thus a "strategic follower", or $\mathrm{SF}$. In the latter case, the efficiency score quantify the percentage by which the SF should increase proportionally all its outputs in order to become efficient. In the second stage, the relative impor tance of the variables (trade offs) is computed. Fi nally, Cluster Analysis of the trade offs is then employed to identify the strategic groups.

Let us begin with the most standard DEA model (Charnes et al., 1978). Consider a set of $S$ $(r=1, \ldots, S)$ firms, each of which individually produces $M(i=1, \ldots, M)$ different outputs for several markets or segments in which it parti cipates (in Section 4 the output variables are designated as variables of scope) having commit ted $N(j=1, \ldots, N)$ different resources. Let $X_{\phi}$ $\left(=x_{j \phi}\right)_{j} \quad 1, \ldots, N$ and $Y_{\phi}\left(=y_{i \phi}\right)_{i} \quad 1, \ldots, M$ denote the in put and output vectors for DMU $\phi$. From this, the efficiency (in our case, competitive advantage) of firm $\phi, h_{\phi}$, can be evaluated through the following program (the so called CCR model): 


$$
\begin{aligned}
\operatorname{Max}_{u_{i}, v_{j}} & h_{\phi}=\left(\sum_{i=1}^{M} u_{i} y_{i \phi} / \sum_{j=1}^{N} v_{j} x_{j \phi}\right) \\
\text { s.t. } & \left(\sum_{i=1}^{M} u_{i} y_{i r} / \sum_{j=1}^{N} v_{j} x_{j r}\right) \leqslant 1 ; \quad r=1, \ldots, S, \\
& \left(u_{i} / \sum_{i=1}^{M} u_{i} y_{i f}\right) \geqslant e ; \quad i=1, \ldots, M, \\
& \left(v_{j} / \sum_{j=1}^{N} v_{j} x_{j f}\right) \geqslant e ; \quad j=1, \ldots, N,
\end{aligned}
$$

where $v_{j}$ and $u_{i}$ are the input and output weights or multipliers (taken as relative or shadow prices). For the DMU under evaluation $(\phi)$, program (1) chooses the weights combination that maximizes its efficiency, which is the weighted ratio of outputs to inputs. The constraints guarantee that the effi ciency score $h_{\phi}$ will not be greater than unity ( $\max$ imum efficiency level), and that the virtual prices are, necessarily, non negative.

The CCR model constructs a piecewise linear envelopment surface (i.e., an empirical frontier) in $R_{+}^{M+N}$, which can be described in terms of its defining facets. The optimal weights that solve program (1) are the coefficients of the linear equa tions that describe these facets. In this sense, $v_{j}^{*}$ and $u_{i}^{*}$ yield a facet of the frontier to DMU $\phi$ :

$\sum_{i=1}^{M} u_{i}^{*} y_{i \phi} \quad \sum_{j=1}^{N} v_{j}^{*} x_{j \phi}=0$.

From this, the production possibility set can be described in terms of (1) the marginal rate of sub stitution between inputs (MRS), (2) the marginal rate of transformation between outputs (MRT), (3) the marginal productivity of outputs relative to inputs, (4) the marginal cost of inputs relative to outputs and (5) the elasticity of substitution (see Rosen et al., 1998; Cooper et al., 2000).

However, when DMU $\phi$ is efficient $\left(h_{\phi}=1\right)$, the virtual weights may not be unique. Thus, we can not directly use the weights obtained from (1) as input or output shadow prices (Rosen et al., 1998). Nevertheless, program (1) distinguishes be tween efficient and inefficient DMUs. It is most interesting to provide an alternative approach to weights computation: The next section is devoted to the identification of a harmonized set of weights for efficient DMUs.

For $h_{\phi}=1$ we can say that DMU $\phi$ is a strate gic leader (SL) that lies on the frontier. When $h_{\phi}<1$, DMU $\phi$ is not on the frontier and we say that $\phi$ is a strategic follower (SF). A strategic fol lower can proportionally contract its inputs by $h_{\phi}$, while still producing at least the same level of outputs.

\subsection{Response capacity of strategic leaders}

As has been pointed out, SG is defined here as a set of firms that convert inputs into outputs while placing an identical valuation on the variables. This is why firms in the same SG will present iden tical reactions to the same external stimuli; or, in other words, why they present similarities in their response capacity.

Since DEA weights reveal a firm's order of pref erences for decision variables, the importance of weights indicates a firm's relative valuation of in puts and outputs. From this, we define response capacity as the trade offs among weights. These trade offs are very informative because marginal relations between variables equal the negative in verse of weights ratios.

Let DMU $\phi$ be a SL whose decisions on the $M$ dimensions of scope and the virtual prices associ ated with each one of them are labeled as, respec tively, $y_{1 \phi}, \ldots, y_{M \phi}$ and $u_{1 \phi}, \ldots, u_{M \phi}$. The response capacity of $\phi$, with respect to the pair of variables $y_{k \phi}, \quad y_{l \phi} \quad(k, l \in i)$, is defined by $\operatorname{MRT}_{y_{k}, y_{l}}^{\phi}=\partial y_{k \phi} / \partial y_{l \phi}$, whose value is equal to the negative of the virtual prices, $\left(u_{l \phi} / u_{k \phi}\right)$. An MRT is defined for each pair of scope dimensions so that the total number of MRTs for a given firm is $M \times M$.

The graphical analysis is portrayed in Fig. 1. As shown, the ratio between the virtual prices $u_{k}$ and $u_{l}$ represents the partial derivatives on the frontier. Thus, the output weights trade off determines a tangency point between the pricing hyperplane and the production possibility frontier (PPF) at point $\mathrm{C}$.

Conceptually, MRTs indicate the slope of the production possibilities frontier in each point 


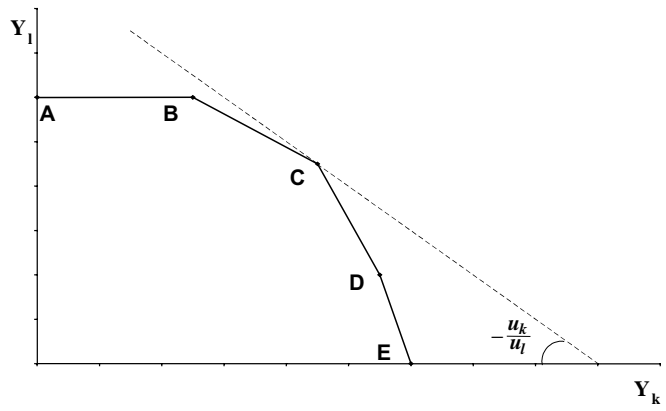

Fig. 1. Graphical representation of the production possibility set and the marginal rate of transformation between two outputs.

$\left(y_{1}, \ldots, y_{M}\right) \in R^{M}$. Given the assumption of linear technology in DEA models, this implies that mul tiple pairs of virtual prices are acceptable for all SLs (Rosen et al., 1998; Cooper et al., 2000). Thus, we cannot directly use the weights from program (1).

In an attempt to find ways to order the MRTs, Rosen et al. (1998) propose an optimization pro gram giving the minimum MRTs (MRS) between outputs (inputs). To see this, let us define $Z=\left(\begin{array}{ll}Y, & X\end{array}\right)^{\mathrm{T}}$ as the matrix of throughputs of all firms; that is a single matrix that contains outputs, $Y=\left(y_{i r}\right)_{i} \quad 1, \ldots, M$, and inputs, $X=\left(x_{j r}\right)_{j} \quad 1, \ldots, N$. In this case, the throughput vector of $\operatorname{firm}^{r} 1, \ldots, S, \phi \in r$, is denoted by $Z_{\phi}=\left(Y_{\phi}, X_{\phi}\right)^{\mathrm{T}}$, where $Y_{\phi}=$ $\left(y_{i \phi}\right)_{i} \quad 1, \ldots, M$ and $X_{\phi}=\left(x_{j \phi}\right)_{j} 1, \ldots, N$. Therefore, $z_{i+j, \phi}$ can be an input or an output. Now let us de note the matrix of weights (for outputs and inputs, respectively) of all firms by $\chi=(u, v)$. Conse quently, the marginal rate (MR) between the $l$ and $k$ variables is defined as $\mathrm{MR}_{k, l} \equiv\left(\partial z_{k}\right)$ $\left.\partial z_{l}\right)=\left(\chi_{l} / \chi_{k}\right)$. When $z_{k}$ and $z_{l}$ correspond to two outputs (inputs), the MR refers to MRT (MRS). Given the special characteristics of the DEA frontier (continuous, but with discontinuous derivatives at the extreme efficient points), Rosen et al.'s proposal (1998) is to compute the deriva tives on the right and on the left, that is the mini mum and maximum ratios of weights (or MRs) at a point, $\mathrm{MR}_{k, l}^{+}$and $\mathrm{MR}_{k, l}^{-}$. To do this, they propose to solve, for each firm on the frontier, the follow ing programs:

$$
\begin{aligned}
& \operatorname{MR}_{k, l}^{+}=\underset{\chi}{\operatorname{Max}}\left(\chi_{l} / \chi_{k}\right) \quad\left(\operatorname{MR}_{k, l}^{-}=\operatorname{Min}_{\chi}\left(\chi_{l} / \chi_{k}\right)\right) \\
& \text { s.t. } \quad z_{\phi}^{\mathrm{T}} \chi=0 \\
& \quad z_{p}^{\mathrm{T}} \chi \leqslant 0
\end{aligned}
$$

where $\chi$ is non negative and $P(P \subset r)$ refers to all strategic leaders. Furthermore, when $k, l$ are out puts, then MR refers to the MRT between out puts. Hence, $\mathrm{MR}^{+}$or the derivative of output $k$ to output $l$, at a point $\phi(\phi \in P)$ on the right, cor responds to the minimum marginal rate of trans formation or the absolute value of the maximum MRT ( $\mathrm{MR}^{-}$corresponds to the absolute value of the maximum or the minimum). The first set of restrictions insures that the firm is situated on the frontier; the second set guarantees that no other firm has an efficiency coefficient greater than one.

The proposal by Rosen et al. (1998), which is graphically portrayed in Fig. 2, is based upon the computation of the maximum $(\beta)$ and minimum $(\alpha)$ slope for each vertex; that is the value for the ratio between the greater and lower virtual prices, respectively.

In our application, we choose as MRT the value $\mathrm{MR}^{-}$(the derivative of the PPF on the left) in or der to avoid infinite values (see in Fig. 2 that the maximum MRT of DMU $\mathrm{C}$ is $\beta$ ).

Program (2) also allows for the identification of the virtual prices of the committed resources. With

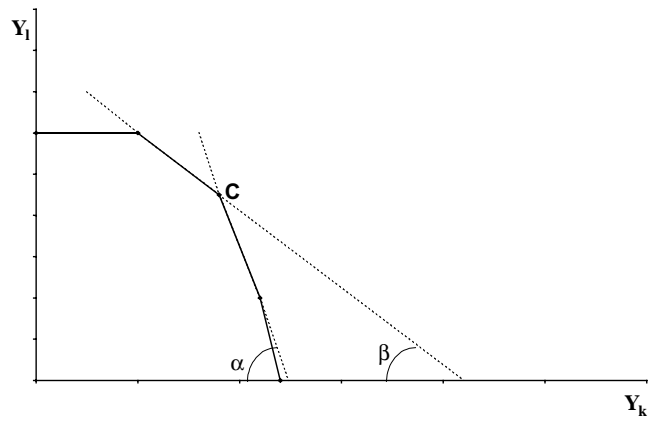

Fig. 2. Maximum $(\beta)$ and minimum $(\alpha)$ marginal rates of transformation of a strategic leader $(\mathrm{C})$. 
this, we can also determine the inputs marginal rates of substitution, MRSs. This time, to avoid infinite values, we choose the minimum MRSs (derivative on the left). Nevertheless, as Rosen et al. (1998) indicate, unbounded solutions can exist in an indeterminate number of cases. In a similar vein, Cooper et al. (2000) point out that some problems arise with this previous approach, because these weights are often very small, so that additional treatment, such as scaling, is needed. This problem, given the multiplicity of input output variables, assumes greater importance in our application, especially. For this reason, we introduce a new set of constraints on program (2), which ensures bounded weights. See in Appendix A how we propose to sort this problem out.

\subsection{Response capacity of strategic followers}

Consider now the situation of strategic follow ers (SFs). Here problems arise because the ap proach presented in the previous section does not work and MRTs cannot be computed. This is due to the fact that MRTs represent partial deriv atives on the frontier (slopes on the PPF at partic ular points) while SFs, as inefficient DMUs, are in the interior of the production possibility set (Cooper et al., 2000).

Another problem related with SFs is that vir tual prices assigned by program (1) define an iden tical MRT for all firms projected to the same linear segment of the PPF. This means that these ineffi cient firms, their respective positions vis à vis the frontier notwithstanding, could appear as if they were in the same SG.

These two limitations can be resolved by using interpolation to determine the weights of ineffi cient DMUs. The interpolation requires two steps. First, the dual of the linear version of program (1) is applied in order to identify activity vectors. Sec ond, taking the MRTs of SLs from program (A.2) and the activity vectors from program (1), it is easy to compute MRTs of SFs.

A more formal description of the interpolation is presented now. First, let us consider program (3):

$$
\begin{array}{ll}
\underset{\alpha_{s}, \lambda, s^{+}, s}{\operatorname{Max}} & z_{\phi}=\alpha_{\phi}+\varepsilon \sum_{i 1}^{m} s^{+}+\varepsilon \sum_{j 1}^{n} s^{-} \\
\text {s.t. } & \alpha_{\phi} Y_{\phi} \quad \sum_{r 1}^{S} \lambda_{r} Y_{r}+s^{+}=0, \\
& \sum_{r 1}^{S} \lambda_{r} X_{r}+s^{-}=X_{\phi}, \\
& \lambda_{r}, s^{+}, s^{-} \geqslant 0 .
\end{array}
$$

When program (3) is solved, we obtain the activity vector $\lambda_{\phi}=\left[\lambda_{\phi 1}, \ldots, \lambda_{\phi S}\right]$; and the effi ciency level, $z_{\phi}$, for each DMU $\phi \in r \quad(r=1$, $\ldots, S$ ), where $z_{\phi}=h_{\phi}$. Depending on its level of competitive disadvantage, the activity vector $\lambda_{\phi}$ indicates the importance of the SL in the determi nation of the targets for the SF.

Fig. 3 shows the graphic representation. Here, for the inefficient firm $\mathrm{H}$, the reference set com prises the DMUs $\mathrm{C}$ and $\mathrm{D}$. The radial distance separating $\mathrm{H}$ from the frontier determines its inef ficiency. For the given commitment of factors, firm $\mathrm{H}$ could become efficient (i.e. situated on the fron tier at point $\mathrm{H}^{*}$ ) by increasing all of its products a proportionate amount of $z_{\mathrm{H}}$. In effect, firm $\mathrm{H}$ could realise the same objective by adjusting its products such that they were a weighted combina tion of the outputs of $\mathrm{C}$ and $\mathrm{D}$, the proportions being $\lambda_{\mathrm{HC}}$ and $\lambda_{\mathrm{HD}}$, respectively.

Since it is not viable to identify the virtual prices for interior points, the second stage consists of defining the MRTs of a SF from the MRTs of the firms on the frontier. More specifically, the response capacity of a strategic follower is calcu lated as the linear combination of the MRs of its

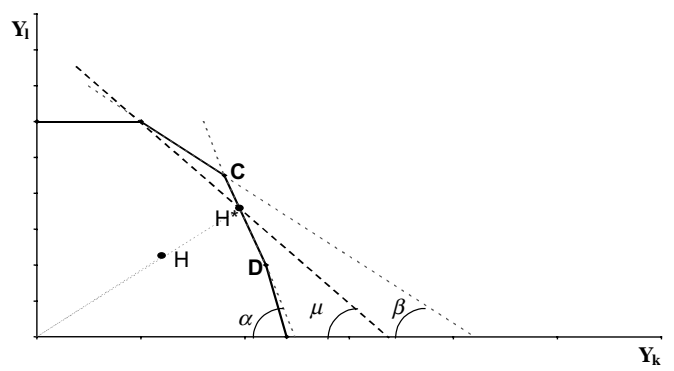

Fig. 3. Identification of the marginal rate of transformation of a strategic follower $(\mathrm{H})$ using interpolation. 
technological reference set. For each pair of out puts $y_{k}$ and $y_{l}(k, l \in i)$, the MRT of a SF $\phi$ is de fined thus:

$$
\begin{aligned}
\operatorname{MRT}_{y_{k}, y_{l}}^{\phi}= & \sum_{r 1}^{S} \lambda_{\phi r}\left(\frac{u_{l r}}{u_{k r}}\right) \\
= & \lambda_{\phi 1}\left(\frac{u_{l 1}}{u_{k 1}}\right)+\lambda_{\phi 2}\left(\frac{u_{l 2}}{u_{k 2}}\right)+\cdots \\
& +\lambda_{\phi S}\left(\frac{u_{l S}}{u_{k S}}\right)
\end{aligned}
$$

where $u_{l r}$ and $u_{k r}$ indicate the virtual prices of out puts $y_{k}$ and $y_{l}$ that satisfy program (A.2) for each firm $r, r=1, \ldots, S$.

Let $r^{*} \subset r$ be the reference group of $\phi$; and $r^{\prime} \subset r$ be the rest of the firms in the sample $\left(r^{*}+r^{\prime}=r\right)$. For $\phi$, the weights that satisfy pro gram (3) are non zero only for the firms that are in its technological reference group, $\lambda_{\phi r^{*}} \neq 0$ $\left(\lambda_{\phi r^{\prime}}=0\right)$. Thus, expression (4) reduces to the weighted sum of the MRTs only of those DMUs that form part of the reference group:

$\operatorname{MRT}_{y_{k}, y_{l}}^{\phi}=\sum_{\forall r^{*}} \lambda_{\phi r^{*}}\left(\frac{u_{l r^{*}}}{u_{k r^{*}}}\right)$.

It can be seen in Fig. 3 that DMU H, situated under the frontier, has two technological refer ences, $\mathrm{C}$ and $\mathrm{D}$. The position on the frontier of these DMUs determine the inefficiency of $\mathrm{H}$ be cause point $\mathrm{H}^{*}$ is nothing more than a convex combination of points $\mathrm{C}$ and $\mathrm{D}$. For firm $\mathrm{H}$, the MRT between outputs $y_{k}$ and $y_{l}, \mathrm{MRT}_{y_{k}, y_{l}}^{\mathrm{H}}=$ $\left(u_{l \mathrm{H}} / u_{k \mathrm{H}}\right)=\mu$, is equivalent to the weighted sum of the marginal rates of transformation of $\mathrm{C}$ and D: $\mu=\lambda_{\mathrm{HC}} \cdot \mathrm{MRT}_{y_{k}, y_{l}}^{\mathrm{C}}+\lambda_{\mathrm{HD}} \cdot \mathrm{MRT}_{y_{k}, y_{l}}^{\mathrm{D}}=\lambda_{\mathrm{HC}}$. $\beta+\lambda_{\mathrm{HD}} \cdot \alpha$. Since the weight of $\mathrm{C}$ is greater than the weight of $\mathrm{D}\left(\lambda_{\mathrm{HC}}>\lambda_{\mathrm{HD}}\right)$, the MRT of DMU $\mathrm{H}$ is closer to $\mathrm{C}$ than to $\mathrm{D}$.

The interpolation we propose helps to resolve the common microeconomic problem of lack of marginal rates for interior points. Usually, DEA cannot distinguish between MRTs for firms shar ing the same technological references (they are projected on the same linear segment of the frontier). Consequently, our approach is a new contribution to DEA research because it allows us to differentiate between them since each inefficient firm is assigned to a specific MRT based on the composition of its respective activity vector.

\section{Spanish banking data}

\subsection{The sample of banks}

Annual data were collected about a sample of two types of banks: Savings and Commercial. Data for savings banks were collected from the publication "Anuario Estadístico de las Cajas de Ahorros Confederadas" published by "Confeder ación Española de Cajas de Ahorros". The data for commercial banks were obtained from the re port "Anuario Estadístico de la Banca Privada" published by "Consejo Superior Bancario". Our initial observation was that the quality levels be tween the two sources were diverse: the data for Savings banks were considerably better. We, there fore, proceeded to analyse the reliability of the data. As a result, the final sample was reduced to 62 Commercial banks and 47 Savings banks. This is much smaller than the original population. There were four main reasons for exclusion: the absence of data (21 commercial banks and two saving banks); the elimination of foreign banking branches (51 commercial banks); the presence of inconsistent data (seven commercial banks); and the elimination of outliers. The elimination of out liers was executed as follows:

Outlier detection is a basic requirement prior to any DEA application. It is common knowledge that the analysis of efficiency with deterministic models is very sensitive to the presence of outliers in the sample. This is due to the fact that the ex treme points determine the efficiency frontier and could affect the marginal rates of the rest of the DMUs. To control for extreme observations, we applied an iterative process, based on Andersen and Petersen's (1993) super efficiency coefficient. As Wilson (1995) points out, in the output ori ented DEA program, excluding units with low val ues of the super efficiency coefficient produces the largest shift in the position of the frontier. Follow ing this reasoning, we ranked units in increasing order of their super efficiency coefficients. This 
enabled us to identify, and then remove, the DMU with the lowest value. We then re calculated the efficiencies and compared the two samples, i.e. the before and the after the DMU exclusion: if we found the difference of the efficiency coefficient between the two samples to be statistically signifi cant, we proceeded to remove such a unit. We then repeated the whole process anew, and so on: the iteration ended when the null hypothesis of equal ity of the efficiency coefficients could not be re jected. Evidently, our procedure is an extension of Wilson's (1995) proposal. The final outcome of the application of this iterative process was the elimination of 12 banking firms (11 commer cial banks and 1 Savings bank).

\subsection{Strategic variables and marginal rates}

As indicated in Section 2, we have followed the concept of the SG defined, first, by Hofer and Schendel (1978) and, later, applied by Cool and Schendel (1987). Hofer and Schendel (1978, p. 25) define the strategy of a firm as "the present and future pattern of deploying of resources and interactions with the environment (scope of the strategy) which indicate how the organization will achieve its objectives", where "the decisions upon scope of the strategy and deploying of resources determine competitive advantage and synergy". ${ }^{1}$ Under this definition of strategy, a SG feeds from "a set of firms competing within an industry on the basis of similar combinations of scope and re source commitments" (Cool and Schendel, 1987, p. 1106). The decisions about scope include the choice of the segments of the firm's target market, the product mix offered in these markets and the geographic reach of the strategy. With regard to the committed resources, human, material and financial resources support the business strategy of the firm. A firm's competitive advantage is the result of its positioning in the product market seg ments in which it participates and of how it applies

\footnotetext{
1 The relevance of each one of the four components of the strategy depends upon the level-corporate, business or functional area of the strategy considered (Hofer and Schendel, 1978).
}

its resources and capacities in each one of them; and is defined as "the advantageous position of a firm vis à vis its competitors by means of its deci sions over resources and/or scope" (Hofer and Schendel, 1978).

Following the proposal of Hofer and Schendel (1978), we summarize the most common varia bles generally used in previous studies devoted to the identification of SGs in the banking indus try (see Walter, 1988; Mehra, 1996). With regard to the scope of the strategy, the multi product nature of the banking firm can be measured in three global aspects, namely: (1) product scope, (2) geographical reach and (3) customer proxi mity:

\section{(1) Product scope}

This dimension of the strategy is captured by six variables:

(S1): (commercial loans)/(financial investments). This ratio captures a bank's orientation towards commercial banking, specialisation in domestic economies and in small and medium firms.

(S2): (portfolio of securities)/(financial invest ments). This ratio determines the extent of banking firm's orientation towards active investments in stock markets.

(S3): (liquid assets)/(financial investments). This ratio indicates the degree of conservatism in the banking activity (maintaining liquid assets avoids risky investments).

(S4): (commissions due to financial services)/ (products of financial activity). Ratio reflecting the diversification away from the traditional banking business towards inno vative banking focused in different services and financial intermediation.

(S5): (Savings and deposit accounts of the private sector)/(total liabilities). This ratio distin guishes between the traditional and con servative banking business, based on the traditional accumulation of family Savings.

(S6): (net position in financial markets)/(total lia bilities). Reflects a novel and aggressive way of capturing funds by means of sophis ticated formulas, such as, for instance, the use of the interbank market. 
(b) Geographical reach

This dimension investigates the extent of the inter regional presence of each bank. To measure geographical reach; we compute the Herfindahl in dex by calculating the ratio of the number of branches of each bank in every Spanish province to the total number of bank branches. Formally, the index is defined as

$H=\sum_{j}^{32}\left(N_{i j} / N_{i}\right)^{2}, \quad 0 \leqslant H \leqslant 1$,

where $N_{i j}$ is the number of branches of the banking firm evaluated in province $j$ and $N_{i}$ is the total number of branches of this bank.

The specific variable used in the DEA evalua tion is

(S7): $1 \quad H$.

\section{(c) Proximity to customers}

The aim of this variable is to capture differences between commercial and saving banks. As reported by Canals (1994), and also by Prior (2003), as a consequence of specific regulation, Spanish savings banks have had to constrain their ambitions of ter ritorial expansion, until recent times. This is why most Savings banks remain situated within their original geographical area, in close proximity to their customers. Obviously, this fact explains why the dimension measuring geographical reach (S7) generally penalizes saving banks. Nevertheless, Savings banks have the advantage of being closer to their domestic customers. To measure customer proximity, a dimension is introduced by means of a variable defined by the Herfindahl index corre sponding to the market quota of each firm $i$ within each province $j(j=1, \ldots, 32)$. More specifically, the variable is defined as

$$
\text { (S8): } \sum_{j=1}^{32}\left(N_{i j} / N_{j}\right)^{2} \text {, }
$$

where $N_{i j}$ is the number of branches in province $j$ for the DMU under evaluation and $N_{j}$ is the total number of branches in this province.

To determine the characteristics of the inputs, we again follow the lead of Cool and Schendel
(1987): We define three variables measuring a firm's commitment of physical, human and finan cial resources:

\section{(R1) Physical capital: (depreciation and amortiza} tion expenses)/(operating income). This var iable captures the importance of the direct costs of fixed assets (buildings and informa tion technology) as a percentage of the oper ating income.

(R2) Human capital: (personnel expenses)/(oper ating income). This variable captures the importance of human re sources as a per centage of the operating income.

(R3) Credit quality: (loan loss provisions and write offs)/(operating income). This ratio reflects the risk inherent in a bank's strategy and the quality of its loans.

Contrarily to Mehra (1996), we do not intro duce any specific variable to represent the struc ture of liabilities because the deposits and financing coming from the inter banking market already figure among the scope variables, and, as such, they would be redundant.

The descriptive statistics are shown in Table 1.

Once the variables measuring the scope of the strategy and the resources committed have been defined, the next step is to select the trade offs to be used in the Cluster Analysis to determine the SGs. According to the theory, the following are the most significant trade offs that take place among the scope variables:

1. (S1/S2) Commercial loans versus portfolio of securities. This trade off points out the dichot omy between commercial banking and invest ment banking.

2. (S1/S3) Commercial loans in respect to treasury. This MRT serves to distinguish between banks specialising in domestic economies and SMFs from those whose investment is focused in financial markets.

3. (S3/S2) Treasury and portfolio of securities. This is a relationship that identifies, by explor ing the strategy of investing assets, risk taking behaviour. 
Table 1

Means, standard deviations and Pearson's correlations

\begin{tabular}{|c|c|c|c|c|c|c|c|c|c|c|c|c|c|c|c|c|}
\hline & & Mean & S.D. & S1 & $\mathrm{S} 2$ & S3 & S4 & S5 & S6 & S7 & S8 & $\mathrm{R} 1$ & $\mathrm{R} 2$ & R3 & ROA & ROE \\
\hline \multirow[t]{8}{*}{ Scope of strategy } & $\mathrm{S} 1$ & 0.5670 & 0.1944 & & & & & & & & & & & & & \\
\hline & $\mathrm{S} 2$ & 0.0534 & 0.0495 & .125 & & & & & & & & & & & & \\
\hline & $\mathrm{S} 3$ & 0.3837 & 0.1934 & $.968^{* *}$ & .125 & & & & & & & & & & & \\
\hline & $\mathrm{S} 4$ & 0.1346 & 0.0870 & $.210^{*}$ & .005 & $.214^{*}$ & & & & & & & & & & \\
\hline & S5 & 0.6716 & 0.2217 & .188 & .017 & $.189^{*}$ & .100 & & & & & & & & & \\
\hline & S6 & 0.2016 & 0.2186 & .167 & .015 & .168 & .091 & $.946^{* *}$ & & & & & & & & \\
\hline & S7 & 0.5153 & 0.3303 & .011 & .121 & .028 & $.409^{* *}$ & $.190^{*}$ & $.218^{*}$ & & & & & & & \\
\hline & S8 & 0.0643 & 0.1152 & .057 & $.291^{* *}$ & .125 & $.189^{*}$ & .162 & .161 & $.246^{* *}$ & & & & & & \\
\hline \multirow[t]{3}{*}{ Resources } & $\mathrm{R} 1$ & 0.0572 & 0.0228 & .009 & .088 & .032 & .153 & .024 & .002 & .172 & .106 & & & & & \\
\hline & $\mathrm{R} 2$ & 0.4008 & 0.1092 & .080 & $.265^{* *}$ & .012 & .174 & .168 & .178 & $.253^{* *}$ & .084 & $.415^{* *}$ & & & & \\
\hline & R3 & 0.0432 & 0.0682 & .058 & .028 & .065 & .009 & $.226^{*}$ & $.219^{*}$ & .086 & .054 & .160 & .141 & & & \\
\hline ROA & & 0.0056 & 0.0138 & .126 & .151 & .164 & .079 & $.202^{*}$ & $.222^{*}$ & .044 & .098 & $.302^{* *}$ & $.536^{* *}$ & .171 & & \\
\hline ROE & & 0.1168 & 0.0896 & $.199^{*}$ & .162 & $.239^{*}$ & .103 & $.380^{* *}$ & $.299^{*}$ & .003 & $.261^{* *}$ & $.295^{* *}$ & $.588^{* *}$ & .094 & $.615^{* *}$ & \\
\hline GP/OM & & 0.2504 & 0.2336 & .039 & .224 & .094 & .129 & $.246^{* *}$ & $.231^{*}$ & .137 & .117 & $.581^{* *}$ & $.790^{* *}$ & $.221^{*}$ & $.780^{* *}$ & $.736^{* *}$ \\
\hline
\end{tabular}

S1: (commercial loans)/(financial investments). S2: (portfolio of securities)/(financial investments). S3: (treasury)/(financial investments). S4: (commissions)/(products of financial activity). S5: (Savings and deposit accounts)/(total liabilities). S6: (net position in financial markets)/(total liabilities). S7: geographical reach. S8: customers proximity. R1: physical capital. R2: human capital. R3: credit quality. ROA: return on assets. ROE: return on equity. GP/OM: (gross profit)/(ordinary margin). $N \quad 109$.

${ }^{*} p<.05$, two-tailed tests

${ }^{* *} p<.01$, two-tailed tests. 
4. (S5/S6) Savings and deposit accounts with respect to financial intermediaries. This ratio clarifies the different strategies that can be used to raise funds.

5. (S2/S4) Investment banking vis à vis innovative banking. This ratio accounts for the disparity between a specialized bank with a narrow range of services and a diversified bank that offers a comprehensive level of financial services.

6. (S7/S8) Geographical reach versus level of serv ice. This captures the conflict between a strategy of disseminating throughout the whole country as opposed to one of focusing on a single prov ince to achieve a greater level of proximity to the client.

With regard to the trade offs among resources var iables, two MRs have been chosen:

7. (R1/R2) Physical capital in relation to human resources. This MR captures the potential dichotomy between a capital intensive technol ogy and a more labor intensive one.

8. (R2/R3) Human resources with respect to credit quality. Relates the expenses due to insolvencies with personnel expense. The rationale behind this is that a greater investment in human capi tal reinforces supervision, and this should be reflected in improvements in the quality of the operations.

\subsection{Analysis}

The first part of the analysis was to quantify marginal rates. This was executed by identifying the response capacity of each firm using the meth odology described in Section 3. Next, an array matrix of MRT and MRS was obtained for each institution by, initially, applying the standard DEA program to obtain the weights followed by the application of program (A.2) to get the mar ginal rates of the strategic leaders. Finally, taking into account the MRs of SLs and the activity vec tors obtained from program (3), the MRs of SFs (expression (5)) were computed.

Once the MRs corresponding to each DMU were known, Cluster Analysis was performed on the basis of the weights. As Ketchen and Shook
(1996) note, previous research has generally relied on Ward's method to cluster firms. However, this method tends to produce clusters with roughly the same number of observations, with solutions that tend to be heavily distorted by outliers. To over come this problem, a solution, advocated in many academic papers (see, for instance, Punj and Ste wart, 1983), is to use a two stage process where a hierarchical algorithm is used to define the number of clusters. The initial results serve as the starting points for iterative partitioning in the second stage.

A correct identification of the number of clusters is indispensable. Thus, multiple methods (Ward, Centroid, Median, Single Linkage, Complete Link age and Average Linkage) were employed in the first stage in order to propose different possible par titions of the sample. From these results, two differ ent tests were carried out. The first was a rule of thumb for selecting the number of clusters pro posed by Harrigan (1985). Harrigan's proposal in volves the examination of the tightness of the groups. For example, using the $R^{2}$, the contribu tion that an additional group would make to the overall fit of the clusters is examined. The process is iterative, the stopping rule being an increase in $R^{2}$ lower than $5 \%$. The second method we used is Fiegenbaum and Thomas's (1990) stopping rule: The clusters obtained must explain at least $65 \%$ of the overall variance, while any additional cluster must add less than $5 \%$ to the incremental variance explained. Finally, we reversed the procedure. We used Discriminant Analysis to calculate the per centage of firms correctly classified in the identified number of groups. Together, these processes al lowed us to identify the appropriate number of strategic groups in existence.

In the second stage, starting from the number of identified strategic groups, each firm was assigned to a group using the non hierarchical $K$ means algorithm. The non hierarchical $K$ means algo rithm has some interesting advantages over hierar chical methods: it is less impacted by outliers and its final solution optimizes within clusters homoge neity and between clusters heterogeneity (Ketchen and Shook, 1996). However, the $K$ means algo rithm has an important shortcoming: It requires that the number of clusters be specified a priori. But, in our case, this has already been solved. 
Finally, to examine whether differences in the selected dimensions exist among the identified SGs, a MANOVA was carried out. Differences among groups for each variable were verified using ANOVA. Additionally, we used Discriminant Analysis to give robustness to our segmentation of the sample.

\section{Strategic groups in Spanish banking industry}

\subsection{Strategic groups based on marginal rates}

Cluster Analysis results suggested that the sam ple should be divided into five strategic groups, as shown in Table 2. The detailed composition of the groups can be found in Appendix B.

Inspection of the centroids of each $\mathrm{SG}$ reveals that, generally, SG2 has the lowest ratios, indicat ing lower costs of strategy change. This result is reasonable when we look at the type of firms that make up the group: they are principally large banks and large Savings banks, which conform to the model of universal banking and have greater capacity to change their strategies.

At the other extreme, SG1 and SG5 (specialized banking) have greater restrictions on changing their strategy in that they face greater costs of change. For SG1, the greater cost of change from

Table 2

Characterization of strategic groups based on marginal rates results of the MANOVA, ANOVA and Discriminant Analyses

MANOVA; $F($ Wilks $) \quad 21.150(p \quad 0.000)$

Discriminant Analysis correctly classifies $89.9 \%$ of the sample

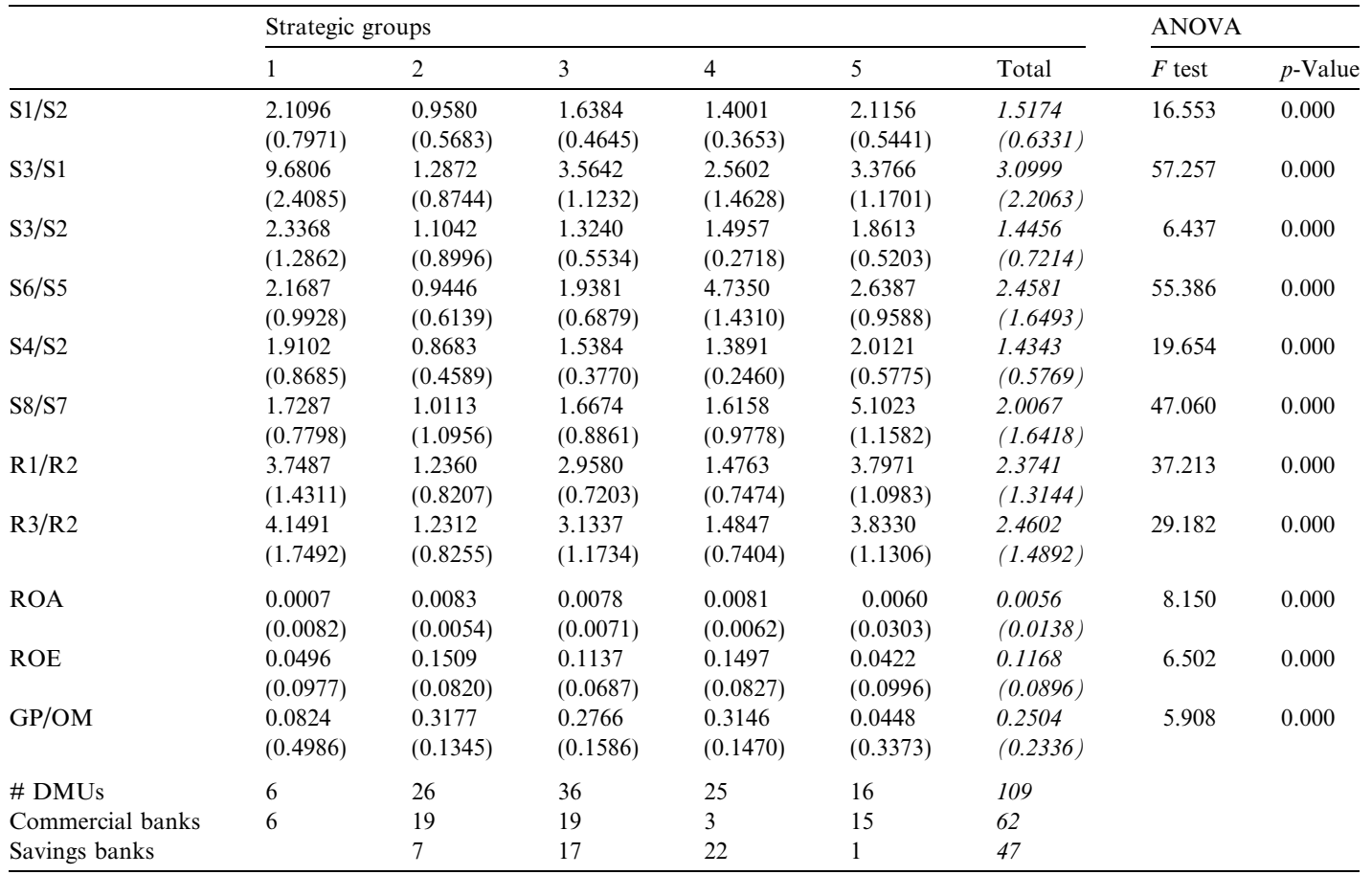

Standard deviations are seen in parentheses.

S1: (commercial loans)/(financial investments). S2: (portfolio of securities)/(financial investments). S3: (treasury)/(financial investments). S4: (commissions)/(products of financial activity). S5: (Savings and deposit accounts)/(total liabilities). S6: (net position in financial markets)/(total liabilities). S7: geographical reach. S8: customers proximity. R1: physical capital. R2: human capital. R3: credit quality. ROA: return on assets. ROE: return on equity. GP/OM: (gross profit)/ordinary margin). 
commercial loans to treasury (high $\mathrm{S} 3 / \mathrm{S} 1$ trade off) indicates that this group places higher value on strategies oriented towards domestic economies and SMEs than on avoiding risk and saving on operating costs. SG1 places the greatest value on the trade off between treasury and portfolio of securities $(\mathrm{S} 3 / \mathrm{S} 2)$ than the other groups, reaffirm ing a risk taking approach. Further still, it is unli kely that SG1 can change its strategy from investment banking (S2) to commercial banking (S1) because for every reduction of one monetary unit in their stocks portfolio, there are important compensations in terms of loans. In other words, for SG1, investments in securities are more valua ble than money lending. This group also has the greatest costs of strategy change from commercial loans (S1) to treasury (S3), from portfolio of secu rities (S2) to treasury (S3), from human resources (R2) to production technology (R1) and from hu man resources (R2) to credit quality (R3). Due to the last trade off, this cluster could be labeled as risky banking. Its high valuation of human capital reinforces this business orientation, as we can see from the trade offs from physical capital (R1) to human capital (R2), and also, from credit quality (R3) to human capital (R2).

SG5 can be labeled as wholesale banking. It is characterized by a focus on geographical reach rather than concentration in a single province (high $\mathrm{S} 7 / \mathrm{S} 8$ ratio). It also has the greatest costs of strategy change between the following pairs of the variables: commercial loans (S1) to portfolio of securities (S2), commissions (S4) to portfolio of securities (S2) and productive technology (R1) to human resources (R2). These ratios suggest that SG5 values a strategy of security investment (S1) more than one of specializing in domestic econo mies and in SMEs (S2); and also more than the usual diversification of traditional banking (S4).

SG3 and SG4 are in an intermediate situation with regard to the costs of strategy change. Never theless, it is worth noting the difficulties that SG4 faces to switch between traditional liabilities (S5) and financial intermediaries (S6) an understand able situation because this group is basically com posed of Savings banks where Savings and deposit accounts play a dominant role in the composition of liabilities. Thus, SG4 can be labeled as tradi tional Savings banks. Finally, we can refer to the SG3 as generalist banking.

When we relate the capacity or costs of strategy change to the indicators of results, we observe that the SGs experiencing the greatest difficulties in attempting to change the orientation of their strat egies have, simultaneously, the worse results. At the opposite extreme SG2, which had the greatest flexibility in the orientation of its strategy, also en joys the best results. This observation holds no matter which indicator we use.

\subsection{Strategic groups based on Cluster Analysis of original decision variables}

Our aim now is to compare the SGs obtained through the proposed method with those obtained from the traditional application of Cluster Analy sis on the original strategic variables as this allows us to establish how well each method performs in determining market segmentation.

Using the previously defined two stage proce dure, Cluster Analysis was applied to the original strategic variables. The results are presented in Table 3, while the composition of SGs is tabulated in Appendix B. A MANOVA and a Discriminant Analysis were carried out to examine the model's ability to separate the observations. Additionally, ANOVA analysis was used to test the significance of the strategic variables among the proposed stra tegic groups. As can be seen, a six cluster solution was obtained.

Allow us now to comment briefly on the results obtained. SG1 represents commercial banking, including the largest Spanish banking firms. They have a broad branch network, emphasizing their focus on retail banking. However, these firms are universal banks and it is not surprising that they also have some business in wholesale banking (for example, portfolio of securities). SG1 is char acterized by a focus on commercial loans, obtain ing funds from the interbanking market.

The banks in SG2 are characterised by innova tive banking. The firms in this group have a very high proportion of earnings from financial services rather than from loans or investments.

SG3 appears to be oriented towards wholesale banking. It is characterized by a focus on attracting 
Table 3

Characterization of strategic groups based on cluster analysis of original decision variables results of the MANOVA, ANOVA and Discriminant Analyses

MANOVA; $F($ Wilks $) \quad 2.942(p \quad 0.000)$

Discriminant Analysis correctly classifies $95.6 \%$ of the sample

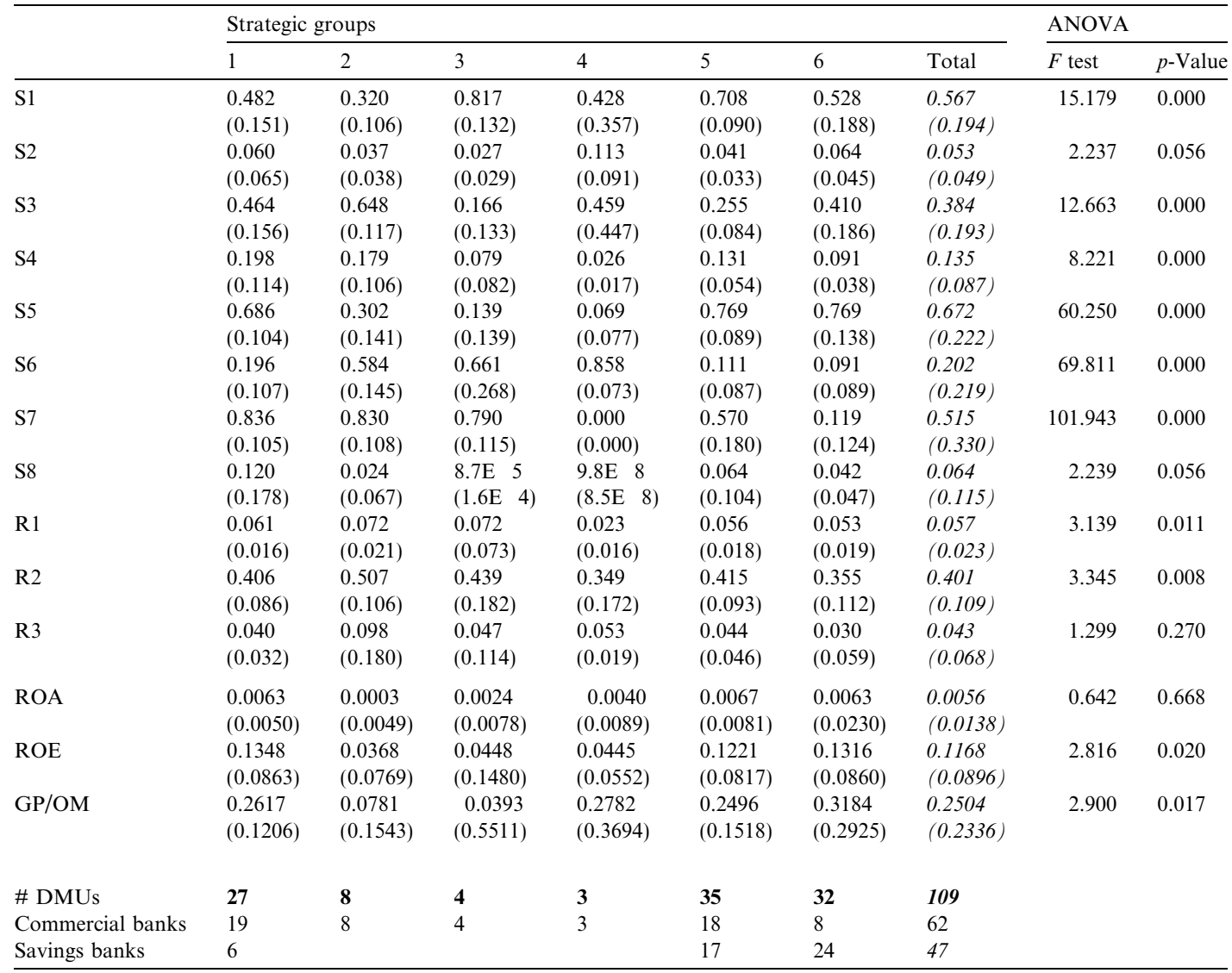

Standard deviations are seen in parentheses.

S1: (commercial loans)/(financial investments). S2: (portfolio of securities)/(financial investments). S3: (treasury)/(financial investments). S4: (commissions)/(products of financial activity). S5: (Savings and deposit accounts)/(total liabilities). S6: (net position in financial markets)/(total liabilities). S7: geographical reach. S8: customers proximity. R1: physical capital. R2: human capital. R3: credit quality. ROA: return on assets. ROE: return on equity. GP/OM: (gross profit)/ordinary margin).

funds by means of sophisticated formulas and func tioning as a resource to the interbanking market. We also find foreign banks, in SG3, that have a poor market quota despite a broad geographical reach, a pattern possibly following the lead of foreign firms.

The key feature of SG4 is investment banking. Rather than commercial loans, this SG is focused on securities investments and on treasury. Where the strategy about liabilities is concerned, $S G 4$ banks capture funds using aggressive sophisticated formulas. They are also sparsely spread across geographical markets.

The orientation in SG5 is intermediation bank ing: $S G 5$ members generally capture funds through 
traditional and conservative formulas (Savings and deposit accounts of the private sector), which they then convert into commercial loans. This is, clearly, a low risk strategy.

Finally, SG6 clusters small Savings banks, where Savings and deposits accounts occupy a dominant place. Furthermore, other key charac teristics of their strategy are high security invest ments most likely in SMEs, some commercial activity and treasury endowments and no risk. The firms in this group are small, both in physical and human capital terms.

From the point of view of the performance group membership linkage, a look at the results in Table 3 suggests that there are no substantial performance differentials across groups. More spe cifically, the ANOVA test shows that groups formed by clustering on the original variables do not exhibit significant differences for the ROA (re turn on assets). In contrast, for the ROE (return on equity) and the GP/OM (gross profit/ordinary margin), the group differences are significant at the $5 \%$ level.

\subsection{Performance analysis}

Strategic group theory suggests that long last ing firm profitability derives from the structure of the industry and that strategic group membership is the primary source of persistent differences in the performance of firms. Our goal here is to examine the extent of statistical association be tween group membership and performance indica tors. A univariate ANOVA test was conducted to examine the association between structure of the industry and the performance of firms. To study the extent of the variability of the indicators that could be explained by strategic group membership, $R^{2}$ tests were computed for each performance indicator.

Following Mehra's (1996), we verify in this sec tion how much better our proposal of determining SGs having started from MRs is at explaining the variability of results than the "traditional" appli cation of Cluster Analysis to the initial strategic variables. The results of this comparison can be found in Table 4. To be able to compare the seg mentations from both methods, we recalculated the six cluster solution obtained from the original strategic variables clustering (model 2B in Table 4 ) in order to impose a division of the sample into five different groups. Model 2A in Table 4 contains the results obtained.

From Table 4, it is evident that SGs based on marginal rates show significant differences across the three performance indicators: the clusters ex plain almost $21 \%$ of the ROA variance, nearly $17 \%$ of ROE variance, and upwards of $15 \%$ of the productivity ratio (gross profit/ordinary mar gin) variance. On the other hand, the capacity of SGs based on clustering on the original variables to explain the variability of the sample depends on the indicator chosen and on the number of clus ters considered. Specifically, the five group solu tion is only significant across one of the performance measures, and only at the $10 \%$ level. However, when six clusters are considered, the groups are significantly different across all per formance dimensions, although the SGs capacity to explain performance differences between groups is still lower than strategic groups based on MRs.

Table 4

ANOVA: $R^{2}$ fit for individual performance measures

\begin{tabular}{|c|c|c|c|c|}
\hline & & ROA & ROE & $(\mathrm{GP}) /(\mathrm{OM})$ \\
\hline SGs based on marginal rates & & $\begin{array}{l}0.209 \\
(0.000)\end{array}$ & $\begin{array}{l}0.169 \\
(0.000)\end{array}$ & $\begin{array}{l}0.154 \\
(0.000)\end{array}$ \\
\hline
\end{tabular}

The significance level of the $F$ values is shown in parentheses.

(GP)/(OM): Gross profit/Ordinary margin. 
The general conclusion that can be drawn from the results shown in Table 4 is that, if one of the requisites for accepting the notion of $\mathrm{SG}$ is the ability to explain differences in results (say, the association between group membership and performance), then the segmentation of banking firms as a function of their strategic response capacity (MRs) exhibits a stronger fit. In other words, SGs based on MRs explain a higher per centage of intra industry performance variance than those obtained from the standard application of Cluster Analysis on the initial variables.

These results reflect a positive relation between the response capacity of banks and superior per formance. A joint analysis of SG characteristics and results clearly reveals that firms with lower cost of strategy change (i.e., low marginal rates) enjoy competitive advantage. This case is very well represented by SG2.

\section{Conclusions}

The concept of a strategic group has merited a great deal of attention within the strategic manage ment and industrial organization literature (McGee and Thomas, 1986). Explaining differ ences in the performance of firms is a fundamental goal of both of these types of literature. Yet still, there is debate in the literature about how strategic groups should be identified (Fiegenbaum and Tho mas, 1990). To address this uncertainty, this study has developed a framework for identifying SGs, and has then applied the framework to test whether the hypothesis of no differences in per formance across groups can be supported. The paper has also proved empirically that this framework has a greater ability to explain intra industry performance differences than the tradi tional analysis.

Our main objective is to find a way to take into account inefficiency when classifying firms into SGs. The basic proposition of this paper is that firms use given inputs in order to achieve certain results, and do so following different strategies. From this, it follows that firms in the same group convert inputs into outputs in the same way, and consequently, an SG can be defined as a set of firms that value inputs and outputs in the same way. In this context, DEA is an excellent tool for segmentation. There are two main reasons to sup port this assertion. First, using DEA efficiency scores calculated for each DMU, comparisons can be made between firms that use similar in puts outputs mix. Second, differences in strategies imply differences in the importance attached to key decision variables. These differences can be perfectly captured through DEA weights. But, usually, there is a problem with DEA weights. They exhibit multiplicity. We have, however, shown in this paper how this limitation can be re solved. Another problem is that weights cannot be computed for inefficient firms because they are in the interior of the production possibility set (Cooper et al., 2000). This problem can, however, be easily overcome by using interpolation and assigning a linear combination of efficient firms' weights to the inefficient ones.

We have been able to test the proposed method through an empirical study of the Spanish banking industry. First, DEA was used to identify the stra tegic leaders (firms lying on the frontier) and to quantify the MRs, which indicate the relative importance of weights with respect to the key deci sion variables. Then, Cluster Analysis was used to group the banks on the basis of the MRs. Finally, statistical tests were employed to investi gate whether any differences in the performance and decision variables are present between the firms.

The results confirmed the potential contribution of our proposal towards a better understanding of the characteristics of SGs. To verify this, we stud ied the strategic groups defined to observe the presence of efficient banks and also for their ability to maximize between group differences. Differ ences between SGs were identified for all the spec ified performance indicators. In order to increase our knowledge about the properties of our pro posal, we compared the SGs composition we had obtained with the one obtained in the traditional way of Cluster Analysis based directly on the stra tegic variables. The results state clearly that the segmentation made on the basis of MRs exhibits a stronger fit because it explains a more substantial percentage of intra industry performance variance. 
Summing up, on the one hand, the SGs obtained using the MRs are very different from those obtained from clustering on the original strategic variables. This empirical evidence sug gests that, for the identification of clusters, it is not just the decisions on the product market dimension that are important but also the relative importance given to these decisions. On the other hand, our proposal is concurrent with very recent literature devoted to the definition of SGs. We now present two examples to clarify this. First, following the cognitive perspective, it is necessary to consider the managers' perspectives on how some firms follow similar strategies (Fombrun and Zajac, 1987). In our specific case, the weights system determines for each firm how managers value their key strategic variables. Thus, firms sharing similar valuation systems determine the configuration of SGs. Second, following the re sources perspective; SGs have to be defined as clusters of firms with similar resources configura tion (Mehra, 1996). Our proposal incorporates the existing relationship between inputs and out puts to define SGs.

MRs provide precise information about the preferences over decision variables made by a group of DMUs. Obviously, it is possible to antic ipate changes in a firm's strategy, but these changes are not necessarily congruent with per formance maximization: if two firms use inputs and outputs in a very different way (say, they be long to separate SGs) and both groups show desir able performance, the convergence between groups never occurs. This explains two usual occurrences: (1) why some firms in an industry achieve greater profits than others; and (2) why firms maintain dif ferent strategies in spite of trying to move to other, apparently more successful, strategies. We can interpret the lack of convergence between groups as a sign of the presence of barriers to mobility. As Hatten and Hatten (1987) pointed out, barriers to mobility should be understood as the costs asso ciated with an eventual change of SG, and such costs should be compared to the potential profits. A preliminary approximation of how important these barriers are in the Spanish banking industry suggests that the performance differences between firms are going to be maintained. The framework proposed in this research opens a new line in the identification of barriers to mobility in the litera ture of SGs. We hope to extend it in the near future.

\section{Appendix A}

Following Rosen et al. (1998) program (2) is linearized with a change of variables, $\rho_{w}=\left(\chi_{w}\right)$ $\left.\chi_{k}\right) ;\left(\rho_{k}=1\right)$ :

$$
\begin{array}{ll}
\operatorname{MR}_{k, l}^{+}= & \operatorname{Max}_{\rho} \rho_{l}\left(\mathrm{MR}_{k, l}^{-}=\operatorname{Min}_{\rho} \rho_{l}\right) \\
\text { s.t. } & \rho_{k}=1, \\
& z_{\phi}^{\mathrm{T}} \rho=0, \\
& z_{p}^{\mathrm{T}} \rho \leqslant 0,
\end{array}
$$

but it is possible that the solution of program (A.1) would be $\rho=\infty$ ( $\rho=0$ in the case of minimiza tion). Given that in our proposal it is important to obtain bounded and non null MRs, we added some additional restrictions that, without altering program (A.1), offered bounded solutions (Sueyo shi et al., 1999, present an alternative proposal to the measurement of upper and lower bounds in the general case of multiple solutions). That was possible redefining Rosen et al. (1998) program adding new restrictions:

$$
\begin{array}{ll}
\operatorname{MR}_{k, l}^{+}= & \operatorname{Max}_{\rho, d} \rho_{l}\left(\mathrm{MR}_{k, l}^{-}=\operatorname{Min}_{\rho, d} \rho_{l}\right) \\
\text { s.t. } & \rho_{k}=1, \\
& z_{\phi}^{\mathrm{T}} \rho=0, \\
& z_{p}^{\mathrm{T}} \rho \leqslant 0, \\
& \rho_{l} \geqslant \rho_{k}+d, \\
& \rho_{k} \geqslant \rho_{k+1}+d, \\
& \ldots \\
& \rho_{M-1} \geqslant \rho_{M}+d, \\
& d>0 .
\end{array}
$$

Maintaining the original program of Rosen et al. (1998), the restrictions added provide bounded solutions (strictly positive in the case of minimization) upon establishing the requirement of equal distance separating successive virtual weights. 
Appendix B. Composition of strategic groups based on marginal rates (vertical) and on cluster original variables (horizontal)

\begin{tabular}{|c|c|c|c|c|c|c|c|c|c|c|c|}
\hline & & Strategic groups & do & rginal rates & & & & & & & \\
\hline & & $\begin{array}{l}\text { Strategic } \\
\text { group } 1\end{array}$ & & $\begin{array}{l}\text { Strategic } \\
\text { group } 2\end{array}$ & & $\begin{array}{l}\text { Strategic } \\
\text { group } 3\end{array}$ & & $\begin{array}{l}\text { Strategic } \\
\text { group } 4\end{array}$ & & $\begin{array}{l}\text { Strategic } \\
\text { group } 5\end{array}$ & \\
\hline $\begin{array}{l}\text { Strategic } \\
\text { groups based }\end{array}$ & SG 1 & & & $\begin{array}{l}\text { BANCO } \\
\text { ATLANTICO }\end{array}$ & 1 & BANCOVAL & 1 & Caja Duero & 1 & $\begin{array}{l}\text { BANCO } \\
\text { GUIPUZCOANO }\end{array}$ & 1 \\
\hline $\begin{array}{l}\text { on cluster } \\
\text { original decision }\end{array}$ & & & & $\begin{array}{l}\text { BANCO ESPAÑOL } \\
\text { DE CREDITO }\end{array}$ & 1 & BANKPYME & 1 & $\begin{array}{l}\text { BANCO } \\
\text { PASTOR }\end{array}$ & 1 & $\begin{array}{l}\text { BANCO DEL } \\
\text { COMERCIO }\end{array}$ & 1 \\
\hline variables & & & & $\begin{array}{l}\text { BBV PRIVANZA } \\
\text { BANCO }\end{array}$ & 1 & $\begin{array}{l}\text { BANCO } \\
\text { DE VITORIA }\end{array}$ & 1 & $\begin{array}{l}\text { C.A. de } \\
\text { GALICIA }\end{array}$ & 1 & $\begin{array}{l}\text { BANCO } \\
\text { DESARROLLO } \\
\text { EC }\end{array}$ & 1 \\
\hline & & & & $\begin{array}{l}\text { BANCO } \\
\text { CENTRAL } \\
\text { HISPANO }\end{array}$ & 1 & BANKOA & 1 & $\begin{array}{l}\text { CAJA ESPAÑA } \\
\text { de Inversiones }\end{array}$ & 1 & SOLBANK SBD & 1 \\
\hline & & & & $\begin{array}{l}\text { BANCO } \\
\text { INVERSION }\end{array}$ & 1 & & & & & $\begin{array}{l}\text { BANCO } \\
\text { GALLEGO }\end{array}$ & 1 \\
\hline & & & & BANCO & 1 & & & & & BANCO & 1 \\
\hline & & & & SABADELL & & & & & & ZARAGOZANO & \\
\hline & & & & BANCO & 1 & & & & & & \\
\hline & & & & URQUIJO & & & & & & & \\
\hline & & & & BANCO & 1 & & & & & & \\
\hline & & & & BILBAO & & & & & & & \\
\hline & & & & VIZCAYA & & & & & & & \\
\hline & & & & BANCO & 1 & & & & & & \\
\hline & & & & POPULAR & & & & & & & \\
\hline & & & & ESPAÑOL & & & & & & & \\
\hline & & & & BANKINTER & 1 & & & & & & \\
\hline & & & & $\begin{array}{l}\text { C.A. y M.P. } \\
\text { de MADRID }\end{array}$ & 1 & & & & & & \\
\hline & & & & Ibercaja & 1 & & & & & & \\
\hline & & & & La Caixa & 1 & & & & & & \\
\hline & SG2 & & & BANCO & 2 & B.N.P. & 2 & & & BANCO LUSO & 2 \\
\hline & & & & SANTANDER & & ESPAÑA & & & & ESPAÑOL & \\
\hline & & & & NEGOCIOS & & & & & & & \\
\hline & & & & BARCLAYS & 2 & & & & & BANCO & 2 \\
\hline & & & & BANK & & & & & & ESPIRITO & \\
\hline & & & & BANCO BANIF & & & & & & $\begin{array}{l}\text { SANTO } \\
\text { BANCO }\end{array}$ & \\
\hline & & & & BANCO BANIF & 2 & & & & & $\begin{array}{l}\text { BANCO } \\
\text { ARABE }\end{array}$ & 2 \\
\hline & & & & & & & & & & ESPAÑOL & \\
\hline & & & & BANCO & 2 & & & & & & \\
\hline & & & & SANTANDER & & & & & & & \\
\hline & SG3 & DEUTSCHE & 3 & FINANZIA & 3 & & & & & CITIBANK & 3 \\
\hline & & BANK CREDIT & & & & & & & & ESPAÑA & \\
\hline & & HALIFAX & 3 & & & & & & & & \\
\hline & & HISPANIA & & & & & & & & & \\
\hline
\end{tabular}


Appendix B (continued)

\begin{tabular}{|c|c|c|c|c|c|c|c|c|c|c|}
\hline & \multicolumn{10}{|c|}{ Strategic groups based on marginal rates } \\
\hline & $\begin{array}{l}\text { Strategic } \\
\text { group } 1\end{array}$ & & $\begin{array}{l}\text { Strategic } \\
\text { group } 2\end{array}$ & & $\begin{array}{l}\text { Strategic } \\
\text { group } 3\end{array}$ & & $\begin{array}{l}\text { Strategic } \\
\text { group } 4\end{array}$ & & $\begin{array}{l}\text { Strategic } \\
\text { group } 5\end{array}$ & \\
\hline \multirow[t]{2}{*}{ SG4 } & PROBANCA & 4 & $\begin{array}{l}\text { BANCO } \\
\text { COOPERATIVO } \\
\text { ESPAÑOL }\end{array}$ & 4 & & & & & & \\
\hline & $\begin{array}{l}\text { DEXIA } \\
\text { BANCO LOCAL }\end{array}$ & 4 & & & & & & & & \\
\hline \multirow[t]{14}{*}{ SG5 } & & & $\begin{array}{l}\text { BANCO DE } \\
\text { VASCONIA }\end{array}$ & 5 & $\begin{array}{l}\text { BANCA } \\
\text { MARCH }\end{array}$ & 5 & $\begin{array}{l}\text { C.E. de } \\
\text { TARRAGONA }\end{array}$ & 5 & $\begin{array}{l}\text { C.E. de } \\
\text { SABADELL }\end{array}$ & 5 \\
\hline & & & BANCO DE & 5 & BANCO & 5 & C.E. de & 5 & BANCA & 5 \\
\hline & & & GALICIA & & DE ALICANTE & & TERRASSA & & CATALANA & \\
\hline & & & $\begin{array}{l}\text { C.A. Municipal } \\
\text { de VIGO }\end{array}$ & 5 & $\begin{array}{l}\text { C.A. y M.P. } \\
\text { de SEGOVIA }\end{array}$ & 5 & $\begin{array}{l}\text { BANCO } \\
\text { HERRERO }\end{array}$ & 5 & $\begin{array}{l}\text { BANCO } \\
\text { SIMEON }\end{array}$ & 5 \\
\hline & & & & & C.E. del PENEDÉS & 5 & BANCA JOVER & 5 & $\begin{array}{l}\text { BANCO } \\
\text { MAPFRE }\end{array}$ & 5 \\
\hline & & & & & $\begin{array}{l}\text { BANCO } \\
\text { DE ANDALUCIA }\end{array}$ & 5 & $\begin{array}{l}\text { C.A. de } \\
\text { CATALUNYA }\end{array}$ & 5 & $\begin{array}{l}\text { CREDIT } \\
\text { LYONNAIS ESP. }\end{array}$ & 5 \\
\hline & & & & & $\begin{array}{l}\text { BANCO } \\
\text { DE MURCIA }\end{array}$ & 5 & CajaSur & 5 & & \\
\hline & & & & & $\begin{array}{l}\text { SIND. BAN. } \\
\text { BARCELONA }\end{array}$ & 5 & $\begin{array}{l}\text { C.A. de } \\
\text { MURCIA }\end{array}$ & 5 & & \\
\hline & & & & & $\begin{array}{l}\text { BANCO DE } \\
\text { EXTREMADURA }\end{array}$ & 5 & BANCAJA & 5 & & \\
\hline & & & & & $\begin{array}{l}\text { BANCO DE } \\
\text { VALENCIA }\end{array}$ & 5 & $\begin{array}{l}\text { C.A. del } \\
\text { MEDITERRÁNEO }\end{array}$ & 5 & & \\
\hline & & & & & $\begin{array}{l}\text { BANCO DE } \\
\text { ASTURIAS }\end{array}$ & 5 & UNICAJA & 5 & & \\
\hline & & & & & BANCOFAR & 5 & $\begin{array}{l}\text { C.A. de } \\
\text { CASTILLA } \\
\text { MANCHA }\end{array}$ & 5 & & \\
\hline & & & & & EUROBANK & 5 & & & & \\
\hline & & & & & $\begin{array}{l}\text { MEDITERRAN. } \\
\text { C. General de A. } \\
\text { GRANADA }\end{array}$ & 5 & & & & \\
\hline
\end{tabular}




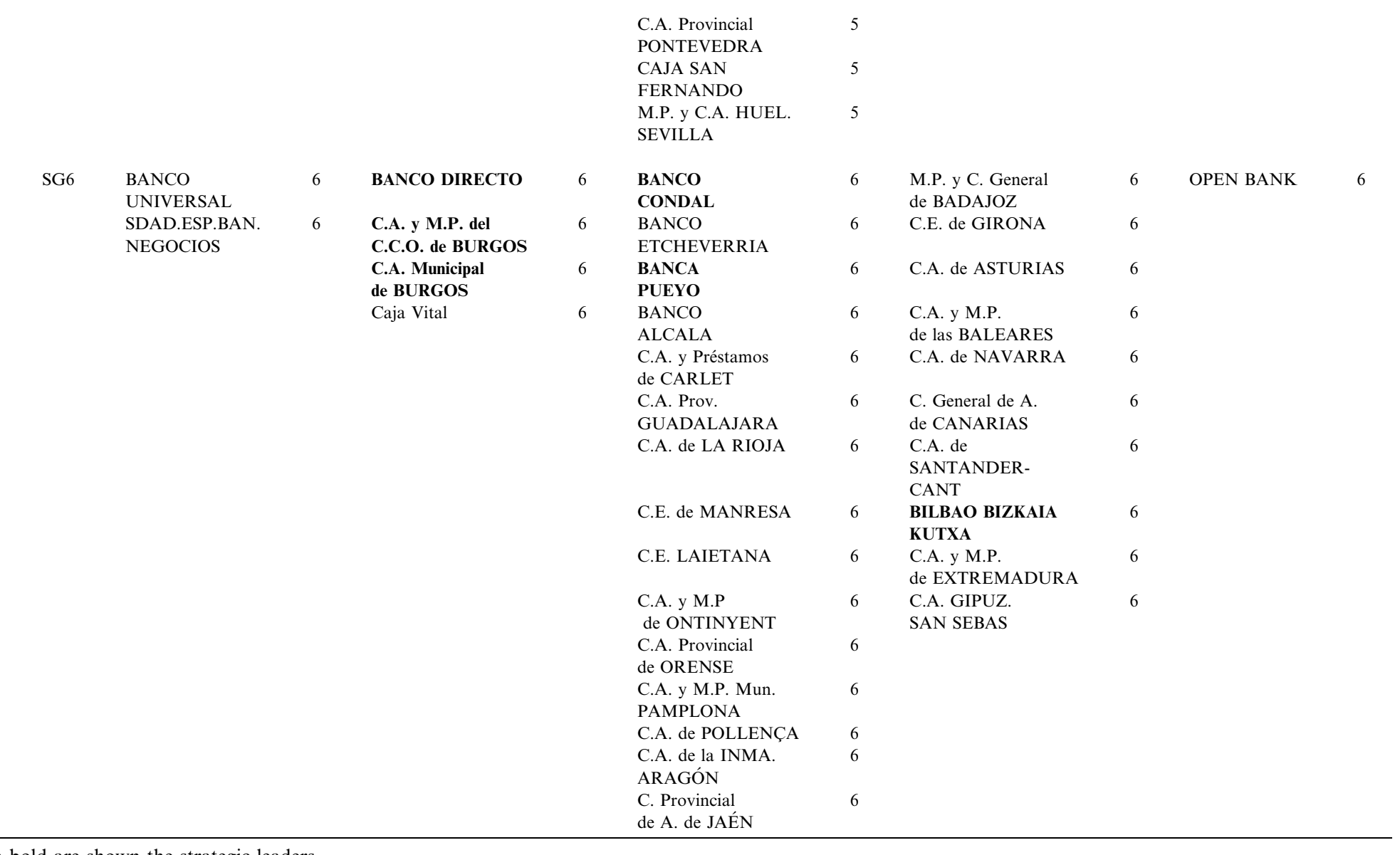

In bold are shown the strategic leaders. 


\section{References}

Andersen, P., Petersen, N.C., 1993. A procedure for ranking efficient units in data envelopment analysis. Management Science 39 (10), 12611264.

Barney, J.B., Hoskisson, R.E., 1990. Strategic groups: Untested assertions and research proposals. Managerial and Decision Economics 11 (3), 187198.

Canals, J., 1994. Competitive Strategies in European Banking. Claredon Press, Oxford.

Caves, R.E., Porter, M.E., 1977. From entry barriers to mobility barriers: Conjectural decisions and contrived deterrence to new competition. Quarterly Journal of Eco nomics 91 (2), 421441.

Charnes, A., Cooper, W.W., Rhodes, E., 1978. Measuring the efficiency of decisions making units. European Journal of Operational Research 6 (2), 429444.

Cooper, W.W., Park, K.S., Pastor, J.T., 2000. Marginal rates and elasticities of substitution with additive models in DEA. Journal of Productivity Analysis 13 (2), 105123.

Cooper, W.W., Seiford, L.M., Tone, K., 2000. Data Envelop ment Analysis: A Comprehensive Text with Models, Applications, References and Dea solver Software. Kluwer Academic Publishers, Boston/Dordrecht/London.

Cool, K.O., Schendel, D., 1987. Strategic group formation and performance: The case of the US Pharmaceutical Industry, 1963 1982. Management Science 33 (9), 11021124.

Day, D.L., Lewin, A.Y., Li, H., Salazar, R., 1994. Strategic leaders or strategic groups: A longitudinal analysis of outliers. In: Charnes, A., Cooper, W.W., Lewin, A.Y., Seiford, L.M. (Eds.), Data Envelopment Analysis Theory, Methodology and Applications. Kluwer Academic Publish ers, Boston/Dordrecht/London, pp. 211234.

Day, D.L., Lewin, A.Y., Li, H., 1995. Strategic leaders or strategic groups: A longitudinal data envelopment analysis of the US brewing industry. European Journal of Opera tional Research 80 (3), 619638.

Dierickx, I., Cool, K.O., 1989. Asset stock accumulation and sustainability of competitive advantage. Management Sci ence 35 (12), 15041513.

Fiegenbaum, A., Thomas, H., 1990. Strategic groups and performance: The US Insurance Industry, 19701984. Strategic Management Journal 11 (3), 197215.

Fombrun, C.J., Zajac, E.J., 1987. Structural and perceptual influences on intraindustry stratification. Academy of Management Journal 30 (1), 3350.

Grifell Tatje, E., Lovell, C.A.K., 1997. The sources of produc tivity change in Spanish banking. European Journal of Operational Research 98 (2), 364380.
Harrigan, K.R., 1985. An application of clustering for strategic group analysis. Strategic Management Journal 6 (1), 5573.

Hatten, K.J., Hatten, M.L., 1987. Strategic groups, asymmet rical mobility barriers and contestability. Strategic Man agement Journal 8 (4), 329342.

Hofer, C., Schendel, D., 1978. Strategy Formulation: Analytical Concepts. West Publishing, St. Paul.

Hunt, M.S., 1972. Competition in the Major House Appliance Industry 1960 1970, unpublished doctoral dissertation, Harvard University.

Ketchen, D.J., Shook, C., 1996. The application of cluster analysis in strategic management research: An analysis and critique. Strategic Management Journal 17 (6), 441458.

McGee, J., Thomas, H., 1986. Strategic groups: Theory, research and taxonomy. Strategic Management Journal 7 (2), 141160.

Mehra, A., 1996. Resource and market based determinants of performance in the US banking industry. Strategic Man agement Journal 17 (4), 307322.

Pastor, J.M., Pérez, F., Quesada, J., 1997. Efficiency analysis in banking firms: An international comparison. European Journal of Operational Research 98 (2), 395407.

Porter, M.E., 1979. The structure within industries and com panies performance. Review of Economics and Statistics 61 (2), 224227.

Porter, M.E., 1980. Competitive Strategy. Free Press, New York.

Prior, D., 2003. Long and short run nonparametric cost frontier efficiency: An application to Spanish savings banks. Journal of Banking and Finance 27 (4), 107123.

Punj, G., Stewart, D.W., 1983. Cluster analysis in marketing research: Review and suggestions for application. Journal of Marketing Research 20 (2), 134148.

Rosen, D., Schaffnit, C., Paradi, J.C., 1998. Marginal rates and two dimensional level curves in DEA. Journal of Produc tivity Analysis 9 (3), 205232.

Sueyoshi, T., Ohnishi, K., Kinase, Y., 1999. A benchmark approach for baseball evaluation. European Journal of Operational Research 115 (3), 429448.

Thomas, H., Venkatraman, N., 1988. Research on strategic groups: Progress and prognosis. Journal of Management Studies 25 (6), 537555.

Wilson, P.W., 1995. Detecting influential observations in data envelopment analysis. The Journal of Productivity Analysis 6 (1), 2745.

Walter, I., 1988. Competitive performance and strategic posi tioning in international financial services. In: Lamb, R., Shrivastava, P. (Eds.), Advances in Strategic Management, vol. 5. JAI Press, Greenwich and London, pp. 6987. 